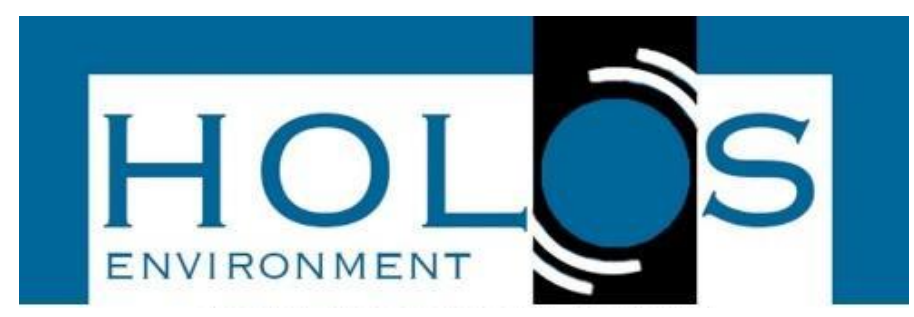

\title{
INCIDÊNCIA DE DOENÇA NO FEIJÃO-CAUPI SUBMETIDO A DIFERENTES DOSES DE BIOFERTILIZANTE
}

\section{INCIDENCE OF DISEASE IN COWPEA SUBMITTED TO DIFFERENT BIOFERTILIZER DOSAGES}

\author{
Mateus Alves de Sousa1; Adao Pires de Almada1; Victor Sousa Avelino1; Iolanda Maria \\ Soares Reis ${ }^{1}$
}

Artigo recebido em: 14/04/2020 e aceito para publicação em: 08/05/2020.

DOI: http:/dx.doi.org/10.14295/holos.v20i3.12387

\begin{abstract}
Resumo: O uso do biofertilizante líquido é uma alternativa sustentável para o uso agrícola, pois trata-se de uma técnica que consiste no emprego de resíduos orgânicos domésticos que são biodegradados por microorganismos, disponibilizando nutrientes para utilização em cultivos agrícolas. E pode ser uma alternativa viável para a produção de feijão-caupi, fornecendo nutrientes adequados para esta cultura, além de propiciar inibição à doenças e insetos. Diante disso, o objetivo neste trabalho foi avaliar a incidência de doença no feijão-caupi submetido a diferentes doses de biofertilizante. O experimento foi desenvolvido no viveiro da Universidade Federal do Oeste do Pará, conduzido em delineamento de blocos ao acaso com cinco repetições. Os tratamentos foram 4 doses de biofertilizante (50, 100, 150 e 200 ml planta -1) e adubação mineral em função da análise do solo. Os dados de doenças foram submetidos a matriz binária de presença e ausência de doença e posteriormente analisados pelo teste TCL a $5 \%$ de probabilidade. O teste não apontou significância para incidência de doenças na adubação mineral com p>5\%, as doses de 50 e 200 ml planta-1 também apresentaram maior incidência de doenças $p>5 \%$. As doses de biofertilizante que apresentaram significância e as menores incidências de doenças no feijão-caupi foram as doses de 100 e $150 \mathrm{ml}$ planta-1 com $\mathrm{p}<5 \%$ e apresentando $9 \%$ de incidência de doenças. $\mathrm{O}$ uso do biofertilizante líquido aplicado no solo inibiu a incidência de doenças no feijão-caupi.
\end{abstract}

Palavras-chave: Nutrição de plantas. Composteira doméstica. Adubação orgânica. Vigna unguiculata (L.) Walp.

\begin{abstract}
The use of liquid biofertilizer is a sustainable alternative for agricultural use, as it is a technique that consists of the use of food waste that is biodegradable by microorganisms, providing food for use in agricultural crops. It can be a viable alternative to cowpea production, providing useful nutrients for this crop, as well as providing disease and insect inhibition. Therefore, the objective of this study was to evaluate the incidence of cowpea disease submitted to different doses of biofertilizer. The experiment was carried out at the Federal University of Western Pará, conducted in a randomized block design with five replications. The procedures were 4 doses of biofertilizer (50,100, 150 and $200 \mathrm{ml}$ plant -1) and mineral fertilization as a function of soil analysis. Disease data were used in the binary matrix of disease presence and absence and subsequently analyzed by the $5 \%$ probability TCL test. The test did not show significance for diseases with mineral fertilization with $p>5 \%$, such as 50 and $200 \mathrm{ml}$ doses of plant -1 also with higher incidence of diseases $p>5 \%$. The doses of biofertilizer that presented significance and the lowest incidence of diseases in cowpea were the doses of 100 and $150 \mathrm{ml}$ plant -1 with $p<5 \%$ and presented $9 \%$ of disease incidence. The use of soil-applied liquid biofertilizer inhibited the incidence of cowpea diseases.
\end{abstract}

Keywords: Plant nutrition. Domestic composer. Organic fertilization. Vigna unguiculata (L.) Walp.

\footnotetext{
1 Universidade Federal do Oeste do Pará (UFOPA) / Instituto de Biodiversidade e Florestas (IBEF). E-mails: (mateussica@gmail.com, adaoalmada1000@hotmail.com, victorave7@gmail.com, iolandareis@outlook.com)
} 


\section{INTRODUÇÃO}

O feijão-caupi [Vigna Unguiculata (L.) Walp.] é uma leguminosa utilizada na alimentação humana e animal usada como feno, ensilagem, além de cobertura do solo, adubação verde e recuperação de áreas degradadas (SILVA et al., 2013). É uma espécie rústica adaptada a regiões de clima quente, úmida ou semiáridas, tendo um amplo potencial adaptativo e tolerância a estresses ambientais (PEREIRA et al., 2013).

A maior parte da produção de feijão-caupi na região Norte é de origem familiar, pois é uma das principais alternativas sociais e econômicas para alimentação e geração de renda, por apresentar elevado valor nutritivo e baixo custo de produção (OLIVEIRA et al., 2011).

Um dos principais fatores limitantes para a produção de feijão-caupi são as doenças, entre elas as mais agravantes são as viroses, já que as infecções ocasionadas por vírus podem ser de forma isolada ou por coinfecções (OLIVEIRA et al., 2011).

Para atenuação de tais problemas estão sendo estudados sistemas alternativos de adubação e manejo fitossanitário. Entre eles estão o uso de fosfatos naturais, estercos curtidos e biofertilizantes, indicados como técnicas para manter o equilíbrio nutricional das plantas e menor suscetibilidade a doenças e pragas (MENEZES JUNIOR; GONÇALVES; VIEIRA NETO, 2014a).

Atualmente a um interesse crescente no uso de biofertilizantes como fertilizante orgânico com o intuito de reduzir o uso de fertilizantes químicos, que causam inúmeros danos ambientais, entre eles: a eutrofização da água, diminuição da microbiota do solo e o incentivo de práticas agrícolas danosas que causam a diminuição da fertilidade do solo a longo prazo (NAYAK; SWAIN; SEN; 2019) .

A adubação orgânica é constituída de resíduos animal ou vegetal e são condicionadores do solo e promovem o melhoramento das qualidades físicas, químicas e biológicas, como a porosidade, aeração, atividade da microfauna e capacidade de retenção de cátions (COSTA JUNIOR et al., 2018).

O biofertilizante líquido é um composto fruto da fermentação da matéria orgânica com água, em meio aeróbio ou anaeróbio, apresenta composição complexa e variável e sua composição nutricional depende do material orgânico utilizado (SILVA et al., 2007). Após sua produção, o biofertilizante é composto por um leque microbiano, com vitaminas, antibióticos, toxinas, quelatos organos-minerais (SANTOS et al., 2017). 
A utilização de fertilizantes orgânicos promove a supressão de doenças de maneira direta ou indireta. A inibição direta de patógenos é potencializada pela competição ou antibiose, quando é indireta se desenvolve a partir de mecanismos de defesa da planta ou de modificações na composição e estrutura das comunidades microbianas no solo (HUANG et al., 2017).

De acordo com Carvalho, Cunha e Silva (2012), o uso de biofertilizante oriundo de digestão anaeróbia de esterco bovino causou inibição de crescimento das seguintes doenças fúngicas, Colletotrichum gloeosporioides (Penz) Sacc., agente da antracnose do maracujá, de Thielaviopsis paradoxa (de Seynes) Höhn, agente da podridão do abacaxi, de Penicillium digitatum (Pers.) Sacc., agente do mofo-verde dos citros, e de Cladosporium herbarum (Pers.) Link., agente da mancha-deprimida do maracujá.

Diante disso, o objetivo neste trabalho foi avaliar a incidência de doenças no feijãocaupi submetido a diferentes doses de biofertilizante.

\section{MATERIAL E MÉTODOS}

O experimento foi desenvolvido em viveiro da Universidade Federal do Oeste do Pará/UFOPA, sob as coordenadas geográficas $2^{\circ} 25^{\prime} 09.4^{\prime \prime S}$ e 5444'31.4"W, Santarém, Pará, entre o período de 28/07/2017 a 08/12/2017. A cidade apresenta clima que se enquadra-se no tipo Am, sendo equatorial úmido com uma estação seca bem definida e outra com altas precipitações, apresenta temperatura média anual variando de 25 a $28^{\circ} \mathrm{C}$, com umidade relativa do ar média de $86 \%$ e precipitação média anual de $1920 \mathrm{~mm}$ (SOUSA et al., 2018).

O solo utilizado como substrato é classificado como um LATOSSOLO AMARELO Distrófico típico e foi coletado em ponto localizado sob as coordenadas $2^{\circ} 41^{\prime} 02.7 " \mathrm{~S}$ e $54^{\circ} 31^{\prime} 55.0$ "W na Fazenda Experimental da UFOPA localizada as margens da rodovia PA 370 no km 37, em Santarém, Pará (Figura 1), a camada de solo coletada foi de 0,20 m. O solo foi passado em peneira com malha de $2 \mathrm{~mm}$ de diâmetro e analisado, (Tabela 1). $\mathrm{O}$ feijão-caupi foi semeado em vasos com capacidade de 5 litros, utilizando $3,5 \mathrm{Kg}$ de solo. 
Figura 1 - Localização do ponto de coleta do solo utilizado como substrato
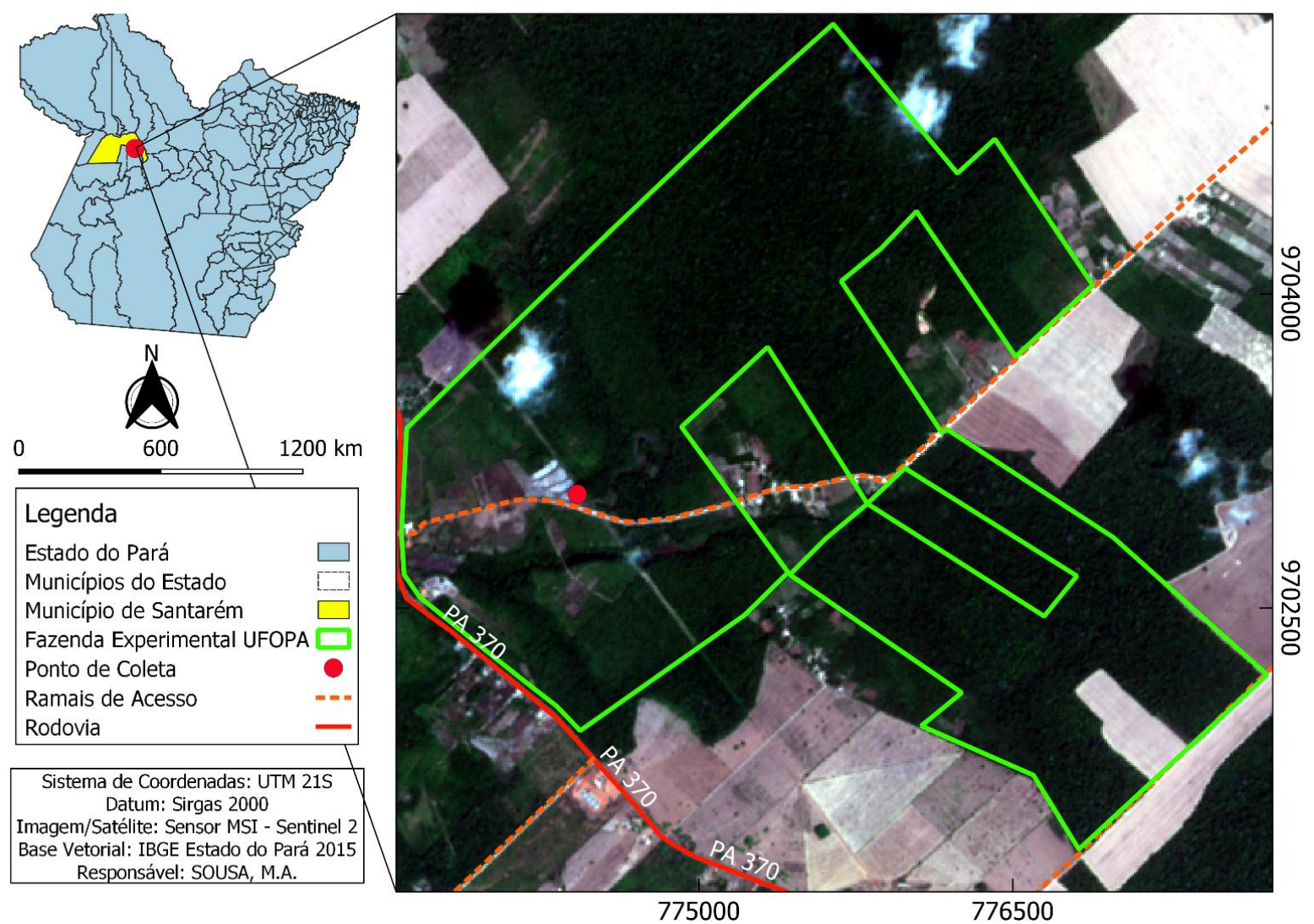

Tabela 1 - Características físico-químicas do solo usado como substrato.

\begin{tabular}{|c|c|c|c|c|c|c|c|c|c|c|}
\hline $\mathrm{pH}(\mathrm{CaCl})$ & M.O. & $\mathrm{Ca}+\mathrm{Mg}$ & $\mathrm{Ca}$ & Mg & Al & $\mathbf{H}$ & $\mathbf{S}$ & $\mathbf{T}$ & $\mathbf{P}$ & K \\
\hline & $\mathrm{g} / \mathrm{dm}^{3}$ & \multicolumn{7}{|c|}{ 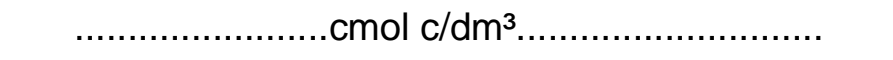 } & \multicolumn{2}{|c|}{$\ldots . \mathrm{mg} / \mathrm{dm}^{3} \ldots}$. \\
\hline 4,7 & 33,9 & 2,8 & 2 & 0,7 & 0,3 & 5 & 2,8 & 8,1 & \multicolumn{2}{|c|}{$3,3 \quad 28, \varepsilon$} \\
\hline $\mathrm{Zn}$ & $\mathrm{Cu}$ & $\mathrm{Fe}$ & $\mathrm{Mn}$ & B & S & Areia & Silte & Argila & V & $\mathrm{m}$ \\
\hline \multicolumn{6}{|c|}{$\ldots \ldots \ldots \ldots . . \mathrm{mg} / \mathrm{dm}^{3} \ldots \ldots \ldots \ldots \ldots \ldots \ldots \ldots \ldots \ldots \ldots$} & \multicolumn{3}{|c|}{$\ldots \ldots \ldots . . . g / k g \ldots \ldots \ldots . .}$. & \multicolumn{2}{|c|}{........\%.......... } \\
\hline 1,5 & 0,4 & 259,9 & 19,8 & 0,5 & 8,7 & 156 & 175 & 669 & 34,9 & 9 \\
\hline
\end{tabular}

M.O - Matéria Orgânica

A produção do biofertilizante foi realizada em composteiras domesticas e seguiu a metodologia de Mendes et al. (2016). A composteira foi preenchida em camadas, com as seguintes porcentagem de componentes: casca de melancia, 15\%; bagaço e casca de laranja, $2 \%$; melão, $5 \%$; esterco bovino, $8 \%$; mamão, $5 \%$; banana, $5 \%$; tomate, $5 \%$; abobora, $5 \%$ e folhas de árvores secas com $50 \%$ do total e ao final passou por análise de fertilidade (Tabela 2). 
Tabela 2 - Características químicas do biofertilizante formulado.

\begin{tabular}{|c|c|c|c|c|c|c|}
\hline pH (água) & $\mathrm{pH} \mathrm{KCl}$ & $\mathrm{Ca}+\mathrm{Mg}$ & $\mathrm{Ca}$ & Mg & Al & $\mathrm{Na}$ \\
\hline & & \multicolumn{5}{|c|}{ 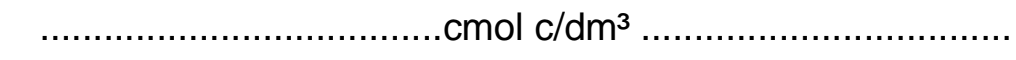 } \\
\hline 9,33 & 8,96 & 3,3 & 2,4 & 0,9 & 0 & 3 \\
\hline $\mathrm{P}$ & $\mathrm{N}$ & $\mathrm{K}$ & \multicolumn{2}{|c|}{ COT } & \multicolumn{2}{|c|}{ M.O } \\
\hline \multicolumn{3}{|c|}{ 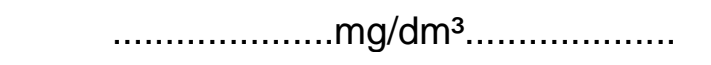 } & \multicolumn{4}{|c|}{$\ldots \ldots \ldots \ldots \ldots . . \mathrm{g} / \mathrm{kg} \ldots \ldots \ldots \ldots \ldots \ldots$} \\
\hline 387,67 & 70 & 85,8 & \multicolumn{2}{|c|}{16,82} & \multicolumn{2}{|c|}{28,99} \\
\hline
\end{tabular}

COT e M.O - Carbono Orgânico Total e Matéria Orgânica

O delineamento adotado foi em blocos casualizados com quatro doses de biofertilizante (50, 100,150, $200 \mathrm{ml}^{\text {planta }}{ }^{-1}$ ) e adubação mineral (controle) totalizando cinco tratamentos com cinco repetições. As doses de biofertilizante foram diluídas em 1.000 $\mathrm{ml}$ de água, aplicando-se $200 \mathrm{ml}$ planta ${ }^{-1}$ por vaso, as aplicações foram feitas de cinco em cinco dias até o estádio R7, a adubação mineral foi aplicada em função da análise de solo. Para a coleta de dados em relação a presença de doença nas plantas, foram feitas inspeções duas vezes por semana, a fim de identificar plantas infectadas, esse procedimento foi realizado durante todo o ciclo da cultura. Com os dados coletados, foi realizado uma matriz binaria de presença e ausência de doença para execução do teste TCL a 5\% de probabilidade e gerou-se um gráfico para a representação descritiva.

\section{RESULTADOS E DISCUSSÃO}

A análise TCL dos dados apresentados na (Tabela 3), observou-se maior incidência de doenças no feijão-caupi no tratamento de adubação mineral com quatro parcelas infectada e $p$-valor não significativo a $5 \%$. As principais doenças identificadas no ensaio foram o Mosaico-severo-do-caupi, Mancha de Cercospora e Mancha Bacteriana, de acordo com diagnose visual (SOBRINHO, 2016). Os tratamentos com biofertilizante teve a dose de $50 \mathrm{ml}$ a mais afetada pela doença $(p>5 \%)$, com três parcelas, a dose de $200 \mathrm{ml}$ apresentou duas parcelas infectadas ( $p>5 \%$ ), enquanto as doses de 100 e $150 \mathrm{ml}$ apenas com uma parcela infectada apresentando $p$-valor menor que $5 \%$ para ausência de doença. Em trabalho realizado por Xiong et al. (2017) onde objetivou suprimir a Murcha de Fusarium (Fusarium oxysporum $f$. sp. vanilla) na cultura da baunilha, onde utilizou-se biofertilizantes enriquecido com fungo e bactéria (Trichoderma guizhouense e Bacillus amyloliquefaciens) respectivamente, além de adubação mineral, o uso do biofertilzante reduziu a incidencia 
de Murcha em comparação a adubação mineral, mas nao apresentou diferença estatisticas, além disso os biofertlizantes apresentaram uma maior densidade e diversidade microbiológica se comparado com o uso da adubação mineral.

Tabela 3 - Valores do teste TCL para dados de presença e ausência de doenças no feijão-caupi.

\section{Quantidade}

Proporção

\begin{tabular}{ccccccc}
\hline Tratamentos & Ausência & Presença & Ausência & Presença & $\mathbf{Z}$ & $\boldsymbol{P}$ - Valor \\
\hline NPK & 1 & 4 & 0,2 & 0,8 & $-0,55$ & 0,57 \\
$50 \mathrm{ml}$ & 2 & 3 & 0,4 & 0,6 & 0,55 & 0,57 \\
$100 \mathrm{ml}$ & 4 & 1 & 0,8 & 0,2 & 3,35 & 0,0007 \\
$150 \mathrm{ml}$ & 4 & 1 & 0,8 & 0,2 & 3,35 & 0,0007 \\
$200 \mathrm{ml}$ & 3 & 2 & 0,6 & 0,4 & 1,67 & 0,09 \\
\hline
\end{tabular}

$p$-valor $<5 \%$ significativo para ausência de doença.

De acordo com Oliveira et al. (2014), a importância do uso do biofertilizante não deve ser dada aos valores quantitativos de seus componentes químicos, que são baixos, mas aos valores qualitativos, pois apresenta uma diversidade microbiológica complexa, além de promover o equilíbrio nutricional e crescimento da planta. Sendo assim, os resultados obtidos, indicam uma melhor nutrição do feijão-caupi usando as doses de 100 e $150 \mathrm{ml}$, pois mitigaram a incidência de doenças nas plantas o que atende a teoria da trofobiose.

A presença de doença na cultura foi atribuída às sementes, pois as mesmas não foram tratadas e não eram sementes comerciais com certificações. A Figura 2, demonstrou que a adubação mineral apresentou $37 \%$ de plantas infectadas, a maior de todos os tratamentos. As doses de biofertilizante que apresentaram maiores porcentagem de infecção foram a de $50 \mathrm{ml}$ com $27 \%$ e a de $200 \mathrm{ml}$ com 18\%, as demais dosagens, ambas apresentaram 9\% de infecção. Esta menor porcentagem de infecção de doenças nos tratamentos do biofertilizante pode indicar ação inibidora a patógenos pelas dosagens. Menezes Junior, Gonçalves e Vieira Neto (2014b) apontam que o uso de biofertilizantes mantém uma nutrição adequada e a planta menos suscetíveis a fitopatógenos e insetos pragas. 
Figura 2 - Porcentagem de plantas doentes

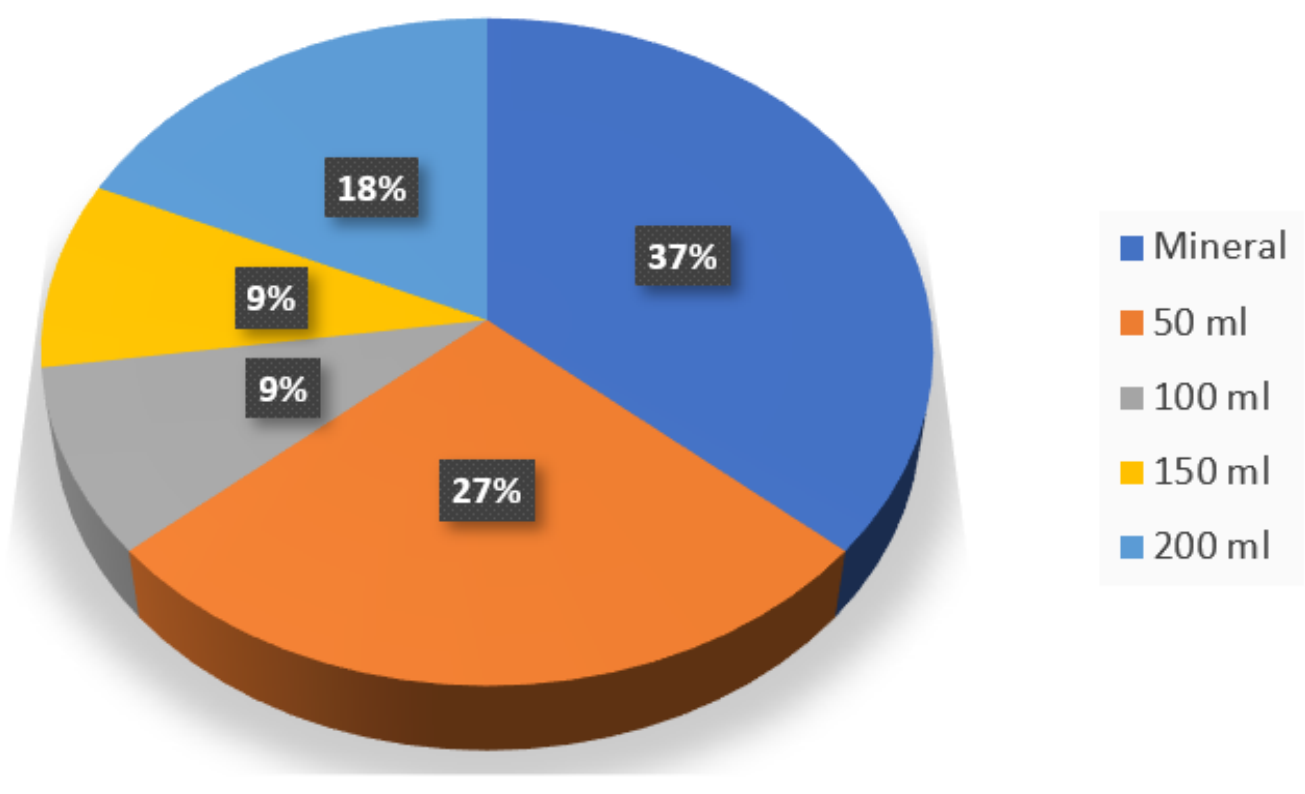

Em trabalho realizado por Condé, Oliveira e Oliveira (2017), onde avaliou-se o uso do biofertilizante Bokashi em uma área contaminada com hérnia da crucíferas, foi observado que a dose de $400 \mathrm{~g} / \mathrm{m}^{2}$ apresentou a menor incidência de hérnia da crucíferas e a menor severidade além de respostas lineares de produtividade.

No ensaio desenvolvido por Ferreira e Tebaldi (2019) onde foi testado diferentes biofertilizantes [Agro-Mos (Cu 3\%, S 2,75\%, Zn 2\%), Cop-R-Quik (Cu 10\%, N 4\%), FitoForce Plus (extrato de folhas e casca de frutos de café) e Soil-Set (Cu 2\%, S 3,75\%, Fe $1,6 \%$, Mn 0,8\%, Zn 3,2\%)] para inibição de crescimento de Xanthomonas campestris pv. Passiflorae, os biofertilizantes FitoForce Plus e Soil-Set inibiram o crescimento Xanthomonas campestris pv. Passiflorae in vitro, os outros produtos não apresentaram efeito inibidor.

\section{CONCLUSÕES}

O uso do biofertilizante líquido oriundo de composteira doméstica aplicado no solo apresenta potencial para inibir a incidência de doenças no feijão-caupi, podendo reduzir custos com defensivos sintéticos, com as doses de 100 e $150 \mathrm{ml}$ apresentando maior poder de inibição. No entanto, é necessário mais estudo com protocolos mais robustos. 


\section{REFERÊNCIAS}

CARVALHO, V.L.; CUNHA, R.L.; SILVA, N.R.N. Alternativas no controle de doenças do cafeeiro. Coffee Science, v.7, n.1, p.42-49, jan./abr. 2012. Disponível em:

http://www.sbicafe.ufv.br/bitstream/handle/123456789/7886/Coffee\%20Science v7 n1 p4249 2012.pdf? sequence $=1$ \&isAllowed $=\mathrm{y}>$. Acesso em: maio 2018.

CONDÉ, V.F.; OLIVEIRA, D.M.F.; OLIVEIRA, J.E.Z. Incidência e severidade de hérnia das crucíferas em repolho (Brassica oleracea $L$. var. capitata) em solo tratado com biofertilizante tipo Bokashi. Ciência e Natura. v. 39, n.1, p. $07-15,2017$. doi:

http://dx.doi.org/10.5902/2179460X21445

COSTA JUNIOR, S.; SILVA, F.B.; MARCHI, E.C.S.; MACHADO, R.C.O.; DELGADO, M.N. Cultivo de alface-americana e feijão- de-corda sob diferentes adubos orgânicos para o Centro-Oeste Brasileiro. Revista Agrogeoambiental. v. 10, n. 2, 2018. doi: http://dx.doi.org/10.18406/2316$\underline{1817 v 10 n 220181170}$

FERREIRA, P.S.F.; TEBALDI, N.D. Métodos de inoculação de Xanthomonas campestris pv. passiflorae em maracujazeiro e biofertilizantes na inibição do crescimento bacteriano in vitro. Summa phytopathol. v.45 n.2, 2019. doi: http://dx.doi.org/10.1590/0100-5405/185793

HUANG, N.; WANG, W.; YAO, Y.; ZHU, F.; WANG, W.; CHANG, X. The influence of different concentrations of bio-organic fertilizer on cucumber Fusarium wilt and soil microflora alterations.

Plos One. 2017. doi: http://dx.doi.org/10.1371/journal.pone.0171490

SOBRINHO, C.A. Pragas da cultura do feijão-caupi. In: EMBRAPA - Empresa Brasileira de Pesquisa Agropecuária. A cultura do feijão-caupi no Brasil. Embrapa Meio-Norte. p.44 a 67. 2016. Disponivel em: https://www.embrapa.br/en/busca-de-publicacoes/-/publicacao/1065595/pragas-dacultura-do-feijao-caupi. Acesso em: jan. 2018.

OLIVEIRA, G.A.; ARAUJO, W.F.; CRUZ, P.L.S.; SILVA, W.L.M.; FERREIRA, G.B. Resposta do feijão-caupi as lâminas de irrigação e as doses de fosforo no cerrado de Roraima. Revista Ciência Agronômica. v.42, n.4, p.872-882, out-dez, 2011. Disponível em: http://ccarevista.ufc.br/seer/index.php/ccarevista/article/view/1178/621. Acesso em: jun. 2018.

OLIVERIA, C.R.R.; FREIRE FILHO, F.R.; NOGUEIRA, M.S.R.; BARROS, G.B.; EIRAS, M.; RIBEIRO, V.Q.; LOPES, A.C.A. Reação de genótipos de feijão-caupi revela resistência às coinfecções pelo Cucumber mosaic virus, Cowpea aphid-borne mosaic virus e Cowpea severe mosaic vírus. Bragantia, v.71, n.1, p.59-66. 2011. Disponível em:

https://ainfo.cnptia.embrapa.br/digital/bitstream/item/71072/1/VirusMosaicoFeijaoCaupiFreire.pdf. Acesso em: maio 2018.

OLIVEIRA, J.R. GOMES, R.L.F.; ARAUJO, A.S.F.; MARINI, F.S.; LOPES, J.B.; ARAUJO, R.M. Estado nutricional e produção de pimenteira com uso de biofertilizantes líquidos. Revista

Brasileira de Engenharia Agrícola e Ambiental. v.18, n.12, p.1241-1246, 2014 Disponível em: http://www.scielo.br/pdf/rbeaa/v18n12/a06v18n12.pdf. Acesso em: jun. 2018.

MENDES, S. M. C.; DIAS, N.S.; LIRA, R.B.; JUNIOR, J.E.E.P.; FREITAS, M.J.; JUNIOR, A.M.F. Composteira caseira: tratamento de resíduos biodegradáveis. I Simpósio de Manejo de Solo e Água. PPGNSA/UFERSA. 06 a 09 de dezembro de 2016. Anais do I Simpósio de Manejo de Solo e Água. Mossoró - Rn. v.18, n.12, p.1241-1246, 2016. 
MENEZES JUNIOR, F. O. G.; GONÇALVES, P. A. S.; VIEIRA NETO, J.. Produtividade da cebola em cultivo mínimo no sistema convencional e orgânico com biofertilizantes. Horticultura

Brasileira. v.32, n.4, p.475-481. 2014. doi: http://dx.doi.org/10.1590/S0102-053620140000400017

NAYAK, M.; SWAIN, D. K.; SEN, R. Strategic valorization of de-oiled microalgal biomass waste as biofertilizer for sustainable and improved agriculture of rice (Oryza sativa L.) crop. Science of the Total Environment . v.682, p.475-784, 2019. doi: https://doi.org/10.1016/i.scitotenv.2019.05.123

PEREIRA, R.F. CAVALCANTE, S.N.; LIMA, A.S.; FILHO, F.C.F.M.; SANTOS, J.G.R. Crescimento e rendimento de feijão vigna submetido à adubação orgânica. Revista Verde de Agroecologia e Desenvolvimento Sustentável. v.8, n.3, p.91 - 96, jul - set , 2013. Disponível em:

https://pdfs.semanticscholar.org/fcfa/104f4c852a111e77f841213b9a1194b38c58.pdf. Acesso em: maio 2018.

SILVA, A. F. PINTO, J.M.; FRANÇA, C.R.R.S.; FERNANDES, S.C.; GOMES, T.C.A.; SILVA, M.S.L.; MATOS, A.N.B. Preparo e uso de biofertilizantes líquidos. Embrapa Semi-Árido. Petrolina, Pe, 2007. Disponível em: https://www.embrapa.br/en/semiarido/busca-de-publicacoes//publicacao/153383/preparo-e-uso-de-biofertilizantes-liquidos. Acesso em: maio 2017

SILVA, E.F.; JUNIOR, A.P.B.; SILVEIRA, L.M.; SANTANA, F.M.S.S.; SANTOS, M.G. Avaliação de cultivares de feijão-caupi irrigado paaa produçaão de grãos verdes em Serra Talhada - Pe.

Revista Caatinga, v. 26, n. 1, p. 21-26, jan.-mar., 2013. Disponível em:

https://periodicos.ufersa.edu.br/index.php/caatinga/article/view/2650/pdf 34

SOUSA, W.N.; BRITO, N.F.; BARROS, I.B.; SOUSA, J.T.R.; SIA, E.F.; REIS, I.M.S. Resposta do feijão-caupi à inoculação de Bradyrhizobium japonicum, adubação nitrogenada e nitrogênio do solo. Revista Agroecossistemas. v.10, n 2, p.298 - 308, 2018. doi:

http://dx.doi.org/10.18542/ragros.v10i2.5167

XIONG, W.; GUO, S.; JOUSSET, A.; ZHAO, Q.; WU, H.; LI, R.; KOWALCHUK, G.A.; SHEN, Q. Bio-fertilizer application induces soil suppressiveness against Fusarium wilt disease by reshaping the soil microbiome. Soil Biology \& Biochemistry . v.114, p.238- 247, 2017. doi:

http://dx.doi.org/10.1016/j.soilbio.2017.07.016 